\title{
Variability of Gait Parameters in Different Daily Situations
}

Dušan ŠIMŠÍK ${ }^{*}$ (SK) dusan.simsik@tuke.sk

Alena GALAJDOVÁ (SK) alena.galajdova@tuke.sk

Zlatica DOLNÁ (SK) zlatica.dolna@tuke.sk

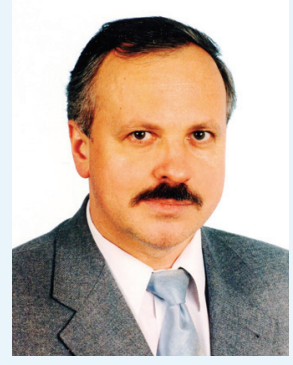

\section{BIOGRAPHICAL NOTES}

prof. Ing. Dušan Šimšík, PhD. Works as a full professor in Biomedical Engineering at the Department of Biomedical Engineering, Automation and Measurement that belongs to Institute of Special Technical Science at Faculty of Mechanical Engineering, Technical University of Kosice. In 1997, under his supervising, first time in Slovakia, the Biomedical Engineering study program was accredited at the University. He has been supervising Master study programme "Biomedical Engineering" and postgraduate study "Bionics and Biomechanics". His research work is related mainly to the Human Motion Analysis Laboratory and Ambient Intelligence Laboratory In the same time he is the Head of the Access centre at Technical University of Košice that serves for students with disabilities. He has been a coordinator and contractor of several research\&development national and international projects (6th and 7th FP, VEGA, KEGA, MVTS, e-Motion, Tempus, Socrates Grundtvig, and Leonadro Da Vinci). He is a member of Biomedical Engineering Research Laboratories (BEL), European Society of Biomechanics (ESB), IMEKOTC 17 and several national professional societies. He is a national contact of Association for the Advancement of Assistive Technology in Europe (AAATE) and European Design for All e-Accessibility Network (EDeAN). Currently he chairs the ICTA Europe Committee of the Rehabilitation International. His research profile covers Robotics, Automated Manufacturing Systems, Modelling and Simulation (1975-1985), later Biomedical Engineering, Rehabilitation Engineering, Assistive Technology for Disabled (1985-till now). He is author and co-author of 5 textbooks, 4 handbooks, over 100 papers published in home and international journals and proceedings from conferences.

Ing. Alena Galajdová, PhD. Is an assistant professor at the Department of Biomedical Engineering, Automation and Measurement, Faculty of Mechanical Engineering, Technical University of Kosice. She also works in the Access Centre as technical advisor for students with disability. She is member of team in Human Motion Analysis Laboratory and Ambient Intelligence Laboratory at Technical University of Kosice. She is a member of Association for the Advancement of Assistive Technology in Europe (AAATE), European Design for All e-Accessibility Network (EDeAN) and ICTA Europe Rehabilitation International. She is involved in several national and international projects (6th and 7th FP, VEGA, KEGA, MVTS, e-Motion, Tempus, Socrates Grundtvig, Leonadro Da Vinci). Her research interest include human motion analysis, assistive technology, neural networks application into biomedical and rehabilitation engineering. She is a co-author of 3 textbooks, 2 handbooks and author of more than 70 papers published in home and international journals and proceedings from conferences. 
Ing. Zlatica Dolná Is a postgraduate student at the Department of Biomedical Engineering, Automation and Measurement that belongs to Institute of Special Technical Science at Faculty of Mechanical Engineering, Technical University of Kosice. She is involved in several national and international projects (6th and 7th FP, VEGA, KEGA, MVTS, Socrates Grundtvig, Leonadro Da Vinci). She works as volunteer in Access Centre and Human Motion analysis Laboratory. She is a member of European Design for All e-Accessibility Network (EDeAN) and ICTA Europe Rehabilitation International. Her professional interest is in biomechanics, human motion analysis, gait pattern study, rehabilitation engineering and assistive technology. She is co-author of 1 textbook, 2 handbooks and an author of more than 30 papers published in home and international conference proceedings and journals.

\section{KEY WORDS}

Human motion analysis, gait parameters, gait pattern, kinematics, SMART system

\section{ABSTRACT}

Gait parameters of ten subjects were recorded in Human Motion Analysis Laboratory at Technical University of Košice to provide data for gait pattern study. Subjects were walking by their self-selected walking speed and accelerated speed of walking in 3 different situations differing with type of cloths. System SMART was used to capture 3D coordinates of subjects' movement ( 6 infrared cameras, $50 \mathrm{~Hz}$ ) for each specific situation and different speed. The motion data available immediately after 3D gait data reconstruction in SMART Tracker software were time dependent position, velocity and acceleration of 25 markers. They provided input for further calculation and kinematic data analysis of human gait. The data analysis conducted in program SMART analyzer provides an overview about gait parameters variability in frame of investigated group of pendants.

\section{INTRODUCTION}

The biomechanical investigation of human movement provides basis for the analysis, description and evaluation of individuals' mobility abilities and specific features. It is based on the knowledge of systematic and functional anatomy of locomotive organs, physiology, neurophysiology as well as biomechanics and bionics, psychology, sociology and other fields of study dealing with the questions of human movement. The paper shows preliminary results of the research for application of human motion systems that results in criminology with specific task to identify persons according to the gait pattern of person. The aim of human motion analysis for purposes of criminological practice is to determine whether two independent records can be used objectively to identify individuals. This type of biometric identification of people seems to bring a new unobtrusive method and enlarge commonly used methods of identification (e.g. fingerprints, hand geometry, palm prints, retina or iris scans). Variability of gait pattern parameters was investigated as the first step.

Human motion analysis research oriented on gait analysis in the past 10 years was able to show that each individual has characteristic style of movement, locomotion. There were several approaches developed to measure and quantify one's gait parameters, and on that basis to recognize a person according to the feature called the dynamic stereotype. Classical approaches are silhouette-based and model-based approaches. Our method is modelbased using videoanalysis and marker system.

The motion analysis experts brought a lot of various methods to measure the kinematics parameters of human motion. Some commercially available systems use special markers attached to specific anatomic landmarks to determine positions of joint centre or body segment. We use such system in our laboratory. SMART system uses markers covered with material that reflects light received by infrared filter of cameras. Besides that we use also marker free approach based on direct definition of model in a video-record frames and further mathematical analysis for calculating an individual's gait pattern.

There are many kinds of passive or active markers used in motion laboratories. Both, the number and the location of the markers, depend on the system, which will track those markers. Although, such systems use different effective methods they still have several limitations. Few of them consider the effect of relative tissue movement that causes the displacement of markers. However, such methods can't be used, if we observe an unknown person, when we don't know his/her parameters, for example one walking on the street. Therefore, our objective in relation to research in biometrical methods for human identification is concentrated on further 
development of marker-free gait analysis system MAFRAN [1, 2] trying to increase an accuracy of evaluated kinematics data through video signal processing. However, the main advantage of the MAFRAN method is that we can use it for evaluation for a video record taken by single camera. In such way we can evaluate record taken by a security camera in real situation and identify gait-linear parameters for the suspected person. Those parameters may be compared with parameters obtained by more precise laboratory system SMART using markers and conditions of controlled environment. For the identification of the person investigated in laboratory with the person recorded in crime situation, the parametrical coincidence has to be approved.

Criminalistic traces with functional and dynamic features are based on automatic process of examination. We assume that they prove dynamical stability and they are essential in dynamic movement stereotypes. Our study of the theoretical principles of a dynamic stereotype of human locomotion and its identical features supported our assumption that the range of differences within the locomotion of each person is smaller than the differences of this expression of locomotion within the sample of population. Another assumption concerns the range of similarities within the locomotion of each person, which is greater than the similarities between this expression and any other expression of locomotion. These principles are surely objectively applicable but their effectivity depends on the method of examination and the experience of the expert.

The main aim of the first phase of our research is to find a specific dynamic stereotype of the functional gait parameters, classify the human motion, and extract parameters with limited variability in the observed group. We look for gait pattern description that is specific and unique so that differs between individuals. A unique dynamic movement stereotype represents a gait signature of person that can be used in different areas in clinical praxis, sports, sports medicine, human identification in criminology, etc. A unique dynamic movement stereotype represents a gait dynamic trace of a person. Human identification is investigated in cooperation with College of Karlovy Vary, Institute of Criminalistic and Forensic Science. [3]

\section{MATERIAL AND METHODS}

The first step in our research was to analyse vari- ability of linear gait parameters of different parts of the human body. The human motion analysis system SMART (BTS Bioengineering) with passive markers is used to capture, reconstruct, evaluate and analyze the gait parameters to get a significant set of parameters for classification of gait patterns. Ten young people without any pathology occurred in musculo-skeletal system with influence on their gait were investigated in our Human Motion Analysis Laboratory. We have studied gait the group of measured subjects, 5 boys M1 - M5 and 5 girls F1 - F5, whose characteristics are described in Fig. 1.

\begin{tabular}{|c|c|c|c|c|}
\hline Subjects & Age [years] & Weight $[\mathrm{kg}]$ & Height $[\mathrm{m}]$ & $\mathrm{BM} \mathrm{I}^{*}\left[\mathrm{~kg} / \mathrm{m}^{2}\right]$ \\
\hline F1 & 25 & 53 & 1.69 & 18.56 \\
\hline F2 & 24 & 54 & 1.68 & 19.13 \\
\hline F3 & 28 & 65 & 1.65 & 23.88 \\
\hline F4 & 27 & 64 & 1.64 & 23.80 \\
\hline F5 & 28 & 58 & 1.60 & 22.66 \\
\hline M1 & 24 & 84 & 1.92 & 22.79 \\
\hline M2 & 26 & 73 & 1.80 & 22.59 \\
\hline M3 & 27 & 91 & 1.87 & 26.02 \\
\hline M4 & 27 & 67 & 1.65 & 24.61 \\
\hline M5 & 32 & 81 & 1.77 & 26.49 \\
\hline Mean value & 26.8 & 69 & 1.73 & 23.05 \\
\hline SD & 2.3476 & 12.9786 & 0.1075 & 2.5884 \\
\hline Range of values & $24-32$ & $53-91$ & $1.60-1.92$ & $18.56-26.49$ \\
* BMI=BodyMass ndex= [weight/(height x height)]
\end{tabular}

Fig. 1 Table of measured subjects and their anthropometric characteristics

The gait parameters of subjects were captured, calculated and evaluated using SMART software packages. We were focused on dynamic parameters describing movement - trajectories of passive markers, their velocity and acceleration. The data provided an input for further calculation and linear analysis of human gait. The reconstructed data were used to derive spatial and temporal gait parameters (step frequency, gait cadence, step length and width, gait cycle phases) and kinematic characteristics (trajectories, joint angles). After process of gathering and reconstruction of data, there is a phase of data evaluation, analysis and method verification. [4]

We have decided to use a whole body model, as we were interested in all segments of human body to study gait pattern. The measurements were done in 3 different situations with three levels of uncertainty. The situations differ in clothing used for motion capture in order to see an influence of cloths and footwear. For each situation measurement with self-selected speed and naturally ac- 
celerated speed was done for future analysis. First phase of gait analysis was devoted to naturally slow, self-selected speed of gait with using tight sporty cloths (see Fig. 2).

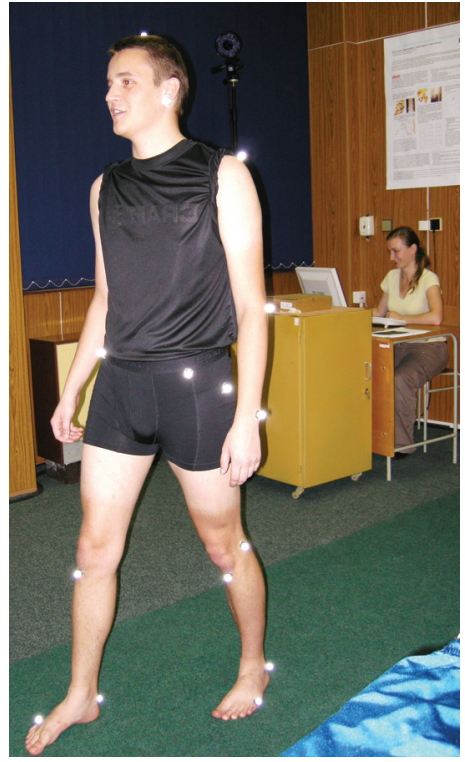

Fig. 2 Example of gait data gathering process in Human Motion Analysis Laboratory

Our model consists of 25 reflex markers placed on selected points of the human body. Anatomically significant parts of human body e.g. joint centres, bony landmarks (distal points of the bones) and musculo-skeletal segments located on head, spine, torso, pelvis, upper and lower extremities were defined before measurements have started. Markers' position was selected based on standard maker sets used internationally and respecting aim of the study with consulting expert from clinical praxis. The result was our own marker set (see Fig.3) inspired by marker sets used in human motion analysis worldwide in research focused on gait analysis $[5,6,7]$. It consisted of markers placed on: a top point of skull (vertex), 7th cervical vertebra (C7), 1st sacral vertebra (Sacrum), ear lobe (R/L_ear), acromioclavicular joint (R/L_shoulder), lateral epicondyle of humerus (R/L_elbow), ulnar styloid process (R/L_wrist), anterior superior iliac spine-pelvis (R/L_ASIS), greater trochanter of femur-hip joint (R/L_gTroch), lateral epicondyle of femur-knee joint (R/L_FEpic), tibial tuberositybelow patella (R/L_TTub), lateral malleolus-ankle joint (R/L_Malleolus), calcaneus (R/L_heel) and 5th metatarsal head-smallest toe (R/L_MheadV).

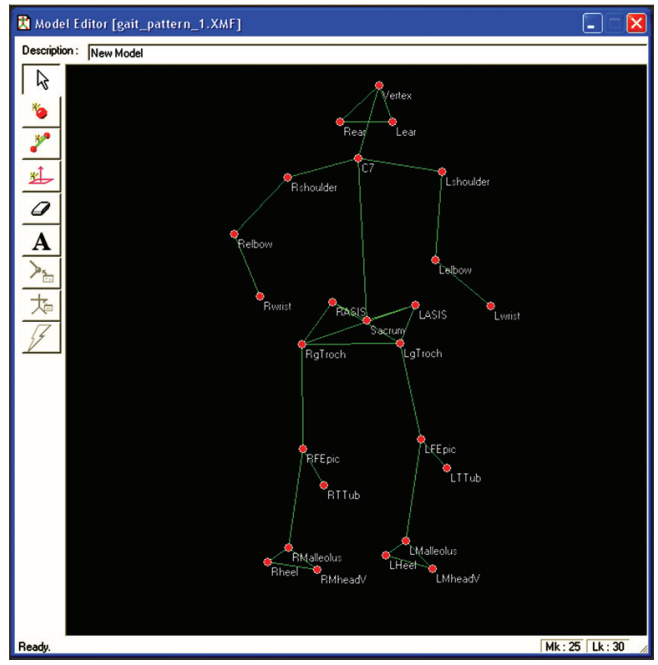

Fig. 3 Marker set model of passive markers location on human body

One of the research aims is to specify a comprehensive set of gait parameters relevant to a specific gait pattern and its classification. The study is based on the gait parameters variability assessment. With scope the set of parameters is called gait pattern to distinguish between subjects. The set of parameters is characterized by low intra individual and high inter individual difference. After the gait data were captured, following process was 3D reconstruction in SMART Tracker software. Reconstruction consists of matching marker model to captured motion data and results in displaying a stick figure representing moving object. It is the most time-consuming part of data evaluation. After the motion is reconstructed we use software package SMART Viewer to:

- Investigate human motion perform an observational study of movement (qualitative gait analysis).

Determine spatial and temporal data. - Follow kinematic data instantly obtained from reconstructed data (quantitative gait analysis).

Stick figure represents moving subject in 3D environment of SMART Tracker and Viewer software that enables to display 3D trajectories and kinematic data as time dependent motion parameters in $x, y, z$ axes (Fig. 4).

In order to investigate human motion we use tools for qualitative analysis (to observe movement in calibrated space) and perform quantitative analy- 
sis (to assess measured data). Kinematics of gait was mainly focused on the change of position, velocities and accelerations were not analyzed in this phase of research.

For data extraction of motion data for further evaluation we have used software package SMART analyzer. Data obtained from SMART Analyzer can be exported into table processor, in format *.xml, accessible e.g. for MS Excel. In SMART Analyzer we first processed the gait data and standardize gait cycle defined by heel strike for each subject. Then we compared data to analyze intra and inter individual difference.

Intra individual variability analysis includes data analysis within each individual. Inter individual differences within a pilot group of 10 subjects describe individual variance of the parameters to distinguish among them.

SMART Analyzer enables user to perform data analysis composing protocols and create reports that display processed data and results of computations. Figure 5 provides an example of how to compute basic statistics from vertex, C7 and Sa-
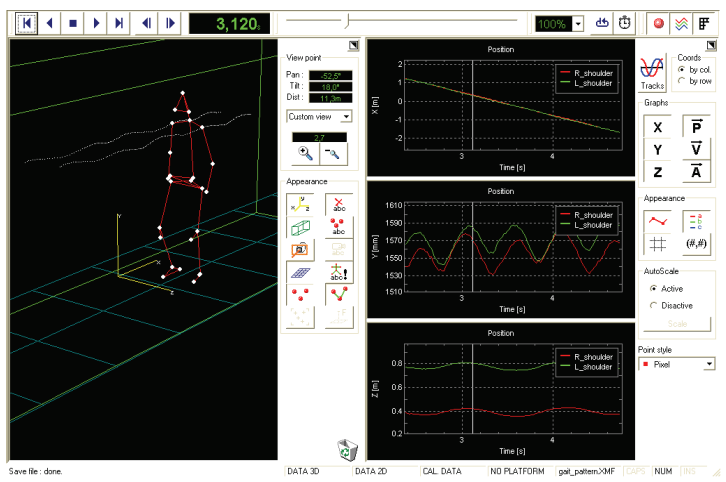

Fig. 4 Gait data representation in SMART Viewer software crum trajectories out of 10 measurements. BlockVertex $Y$ multi calculates mean and standard deviation of vertex trajectory (projection of trajectory in the $y$-coordinates) per each time frame of captured data consisted of 10 measurements per subject.

\section{RESULT}

\section{Qualitative motion analysis - observational gait analysis results}

From captured motion we can see that within 10 measurements of each individual there is typical motion pattern, walking style observed. It is also a basic assumption for our research in the field of gait pattern study. We have assessed characteristic movement of upper extremities, influence of anthropometry measures on human posture (angle of femur in frontal plane, inclination of pelvis in sagital plane, angle of trunk bending forward, and others), rhythm of movement, symmetry of overall locomotion, and symmetric movement of body segments; evaluate the dominant side of body, respectively.

\section{Spatial and temporal gait parameters analysis re- sults}

The spatial and temporal gait parameters (Fig. 6) included gait characteristics:

Stride length (gait cycle length): functional unit of gait, distance between sequential corresponding points of contact by the same foot, mostly defined as heel strike to heel strike of the same foot, simply said each stride comprises in 2 steps (healthy adults: 1,3-1,6 m).

Stride time (gait cycle duration): 1 gait cycle duration in time (healthy adults: 1,5 s).

Walking speed: speed equals distance/time (healthy adults: $80 \mathrm{~m} \cdot \mathrm{min}^{-1}$ ).

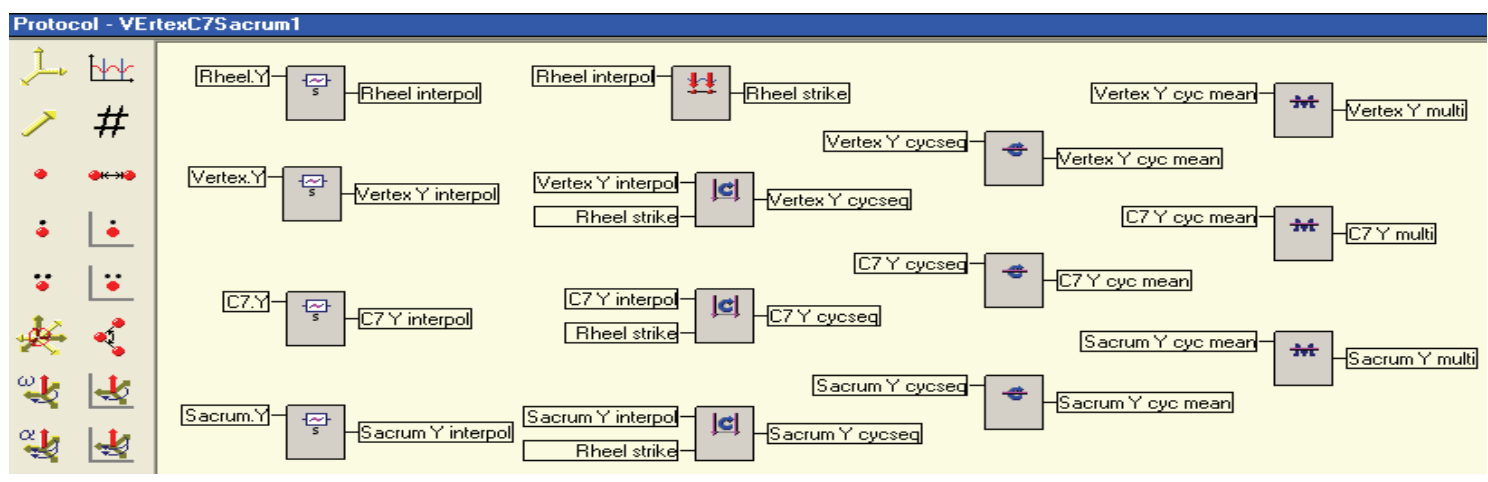

Fig. 5 Example of protocol created in SMART Analyzer 


\begin{tabular}{|c|c|c|c|c|c|c|c|c|c|c|c|c|c|c|}
\hline Measured subject F4 & Body side & 1 & 2 & 3 & 4 & 5 & 6 & 7 & 8 & 9 & 10 & Mean & SD & $\mathrm{CV}$ \\
\hline \multirow{2}{*}{ Stride length [m] } & Right & 1.25 & 1.29 & 1.20 & 1.28 & 1.15 & 1.18 & 1.22 & 1.18 & 1.18 & 1.14 & 1.21 & 0.05 & 4.28 \\
\hline & Left & 1.25 & 1.23 & 1.27 & 1.27 & 1.15 & 1.18 & 1.23 & 1.20 & 1.18 & 1.13 & 1.21 & 0.05 & 4.07 \\
\hline \multirow{2}{*}{ Stride time [s] } & Right & 1.14 & 1.12 & 1.12 & 1.06 & 1.14 & 1.14 & 1.12 & 1.14 & 1.08 & 1.14 & 1.12 & 0.03 & 2.53 \\
\hline & Left & 1.12 & 1.14 & 1.10 & 1.06 & 1.16 & 1.14 & 1.10 & 1.14 & 1.10 & 1.12 & 1.12 & 0.03 & 2.59 \\
\hline \multirow{2}{*}{ Walking speed $[\mathrm{m} / \mathrm{s}]$} & Right & 1.10 & 1.15 & 1.07 & 1.21 & 1.01 & 1.04 & 1.09 & 1.04 & 1.09 & 1.00 & 1.08 & 0.06 & 5.95 \\
\hline & Left & 1.12 & 1.08 & 1.16 & 1.19 & 0.99 & 1.03 & 1.11 & 1.05 & 1.07 & 1.01 & 1.08 & 0.07 & 6.01 \\
\hline \multirow{2}{*}{ Cadence $[\mathrm{step} / \mathrm{min}]$} & Right & 105.26 & 107.14 & 107.14 & 113.21 & 105.26 & 105.26 & 107.14 & 105.26 & 111.11 & 105.26 & 107.21 & 2.79 & 2.60 \\
\hline & Left & 107.14 & 105.26 & 109.09 & 113.21 & 103.45 & 105.26 & 109.09 & 105.26 & 109.09 & 107.14 & 107.40 & 2.82 & 2.63 \\
\hline \multirow{2}{*}{ Step length [m] } & Right & 0.58 & 0.57 & 0.61 & 0.60 & 0.55 & 0.55 & 0.56 & 0.55 & 0.54 & 0.52 & 0.56 & 0.03 & 4.77 \\
\hline & Left & 0.57 & 0.56 & 0.61 & 0.59 & 0.53 & 0.55 & 0.57 & 0.56 & 0.55 & 0.53 & 0.56 & 0.02 & 4.41 \\
\hline \multirow{2}{*}{ Step width [m] } & Right & 0.10 & 0.04 & 0.13 & 0.09 & 0.11 & 0.04 & 0.04 & 0.04 & 0.03 & 0.06 & 0.07 & 0.04 & 52.90 \\
\hline & Left & 0.06 & 0.06 & 0.11 & 0.03 & 0.08 & 0.04 & 0.03 & 0.05 & 0.07 & 0.02 & 0.06 & 0.03 & 46.71 \\
\hline \multirow{4}{*}{ Gait cycle phases [\%] } & Right stance & 59.65 & 60.71 & 58.93 & 60.38 & 63.16 & 59.65 & 58.93 & 59.65 & 55.56 & 61.40 & 59.80 & 1.96 & 3.28 \\
\hline & Right swing & 40.35 & 39.29 & 41.07 & 39.62 & 36.84 & 40.35 & 41.07 & 40.35 & 44.44 & 38.60 & 40.20 & 1.96 & 4.88 \\
\hline & Left stance & 58.93 & 59.65 & 58.18 & 56.60 & 60.34 & 61.40 & 58.18 & 59.65 & 58.18 & 62.50 & 59.36 & 1.74 & 2.92 \\
\hline & Left swing & 41.07 & 40.35 & 41.82 & 43.40 & 39.66 & 38.60 & 41.82 & 40.35 & 41.82 & 37.50 & 40.64 & 1.74 & 4.27 \\
\hline
\end{tabular}

Fig. 6 Spatial and temporal gait parameters - mean values, SD and CV for 1 subject (F4)

Cadence: number of steps per unit time (healthy adults: 90 - 120 steps. $\mathrm{min}^{-1}$ ).

- Step length: distance between sequential corresponding points of contact by opposite feet, simply said 1 step of 1 foot (healthy adults: $400-600 \mathrm{~mm}$ ). - Step width: distance between centre of the heels, usually measured at the beginning of double stance, during heel strike (healthy adults: 60 - 100 $\mathrm{mm})$.

- Gait cycle phases: gait cycle is divided into stance (foot carries body weight in contact with surface) and swing phase, stance is $60 \%$ and swing is $40 \%$ of whole gait cycle.

In our pilot study if we look at spatial and temporal parameters of an individual subject, all the parameters are showing symmetry of the right and left body side, except step width and gait phases. Measured data for intra individual comparison of 10 measurements within subject F4 (Fig. 6) approve that there is relatively low data variability of stride time, cadence and step length. On the other side, the highest variability of step width and walking speed was found during walking of each subject. This can be concluded in general, for 10 subjects. The most variable parameter - step width for both right and left side - achieved values of CV varying form $8-88 \%$. Inter individual comparison results achieved from descriptive statistics - show that the most variable was step width with the highest coefficient of variance. Walking speed, step length and gait phases indicated moderate variability (Fig. 7). When comparing several measured subjects and their spatial and temporal data we can conclude:

- Intra individual analysis (within 10 measure-

\begin{tabular}{|c|c|c|c|}
\hline Measured subject & Total & Total & Total \\
mean & SD & CV \\
\hline Gait parameter & 1.21 & 0.08 & 6.34 \\
\hline \multirow{2}{*}{ Stride length [m] } & 1.23 & 0.07 & 5.76 \\
\hline \multirow{2}{*}{ Stride time [s] } & 1.17 & 0.05 & 4.50 \\
\cline { 2 - 4 } & 1.16 & 0.06 & 5.16 \\
\hline \multirow{2}{*}{ Walking speed [m/s] } & 1.05 & 0.08 & 8.06 \\
\cline { 2 - 4 } & 1.07 & 0.09 & 7.88 \\
\hline \multirow{2}{*}{ Cadence [step/min] } & 103.32 & 4.64 & 4.64 \\
\cline { 2 - 4 } & 104.17 & 5.18 & 4.96 \\
\hline \multirow{2}{*}{ Step length [m] } & 0.53 & 0.03 & 10.59 \\
\cline { 2 - 4 } & 0.51 & 0.03 & 9.66 \\
\hline \multirow{2}{*}{ Step width [m] } & 0.13 & 0.03 & 34.64 \\
\cline { 2 - 4 } & 0.12 & 0.02 & 41.49 \\
\hline \multirow{2}{*}{ Stance [\%] } & 58.07 & 3.63 & 6.49 \\
\cline { 2 - 4 } & 41.93 & 3.63 & 8.32 \\
\hline \multirow{2}{*}{ Swing [\%] } & 58.03 & 3.56 & 6.24 \\
\cline { 2 - 4 } & 41.97 & 3.56 & 8.36 \\
\hline
\end{tabular}

Fig. 7 Mean, standard deviation and coefficient of variance for spatial and temporal parameters of group of 10 subjects

ments per 1 subject) demonstrates the lowest variability (highest reliability of data) of stride time, cadence and step length.

Inter individual analysis (within 10 subjects in the group) proves step width as the most varaibel parameter.

Values and symmetry of spatial and temporal gait parameters show that subjects' parameters were within physiological limits.

When comparing results of intra and inter individual comparison of spatial and temporal data of measured subjects, the most appropriate parameters to investigate the differences between people are: stride time, step length and stance phase. 
Afterwards the analysis of variance, ANOVA test as parametric and Kruskal-Wallis test as non-parametric test of data variance was used to find statistically significant differences. Afterwards, we examined Scheffe follow-up test $(p<<0,05)$ to see how much subjects differ from each other.

The result of the testing is the order of the spatial and temporal parameters according to the level of significant differences represented by percentage of difference between 10 measured subjects. All parameters prove variability higher than $25 \%$ except of gait phases not included in the order on the Fig. 8.

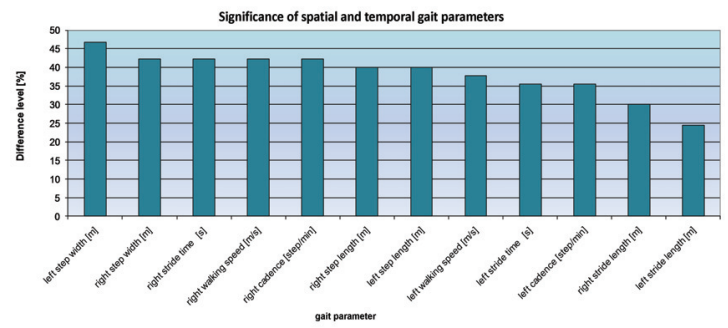

Fig. 8 Order of spatial and temporal gait parameters according to level of significant differences of 10 measured subjects

\section{KINEMATIC DATA ANALYSIS}

We have studied how the motion data, kinematic characteristics, vary within individuals and between the individuals. From trajectories analysis of 25 markers in sagittal plane we can display variability of data for each individual and for the group of subjects. First the trajectories have to be changed into the comparable form in order to avoid influence of the anthropometric data e.g. height of posture, length of lower extremity and others. Trajectories have been modified - normalized; they result in number from 0 to 1. Fig. 9 displays graphically that the left wrist trajectory is the most different for 10 subjects.

Small data variability is found in all trajectories, because the level of significant differences between subjects reached maximum of $11 \%$. The most variable was wrist (11\%), lateral knee (9\%) and elbow trajectory (7\%).

Figures 10 and 11 display graphs of angular parameters: mean value of right elbow angle (Fig.10) angle and right knee angle (Fig. 11). It is visible on the time dependent change of angular character- istics of movement that the variability between measured subjects changes more critically greater for elbow angle and less significant for knee angle. From inter individual comparison of angular data we can conclude that greater the variability, stronger parameter for significant difference in the process of comparing the subjects.

Comparison was made also assessing minimal and maximal value that angle reached and also individual range of motion (ROM) in particular joint. As Figure 12 displays, data for minimal and maximal flexion/extension angle of elbow and knee joint and dorsal/plantar flexion angle in case of ankle joint show how variable the data are spread is - including no dependence on range of motion (ROM) of particular joint. Further analysis is necessary to explore the dependence or pattern in peak values of angles.

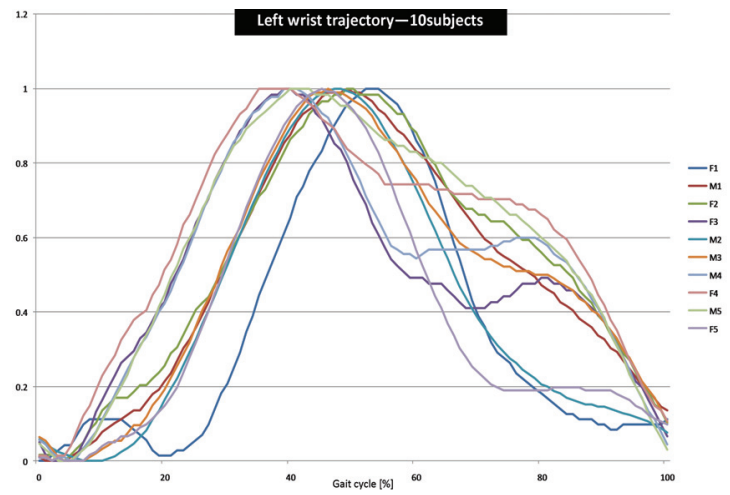

Fig. 9 Comparison of left wrist trajectories for 10 subjects

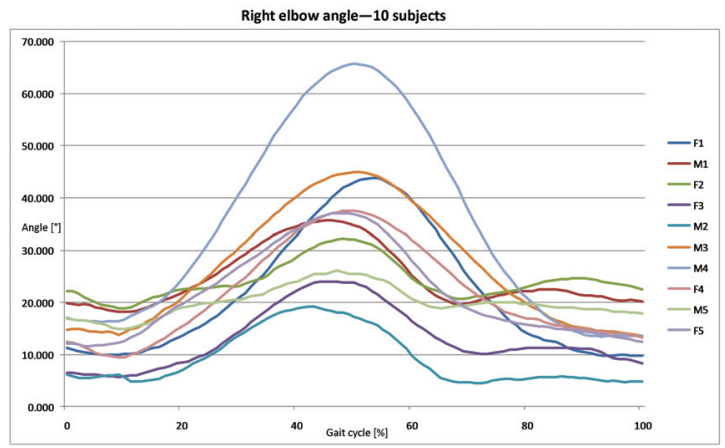

Fig. 10 Comparison of right elbow angle (flexion and extension) for 10 subjects 


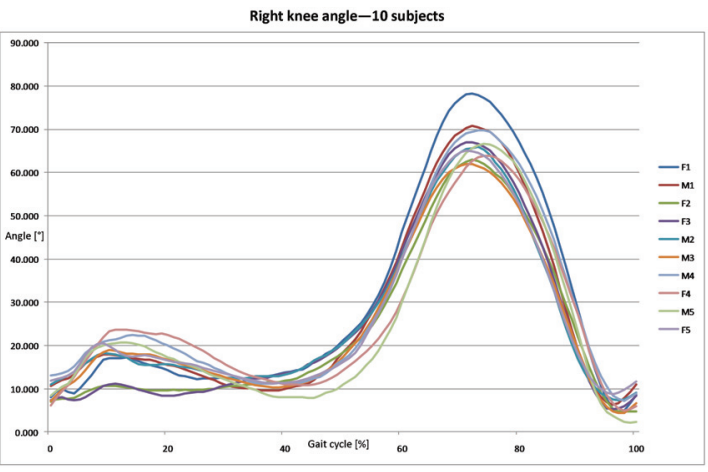

Fig. 11 Comparison of right knee angle (flexion and extension) for 10 subjects

When analyzing deviation of elbow, knee and ankle angles of 10 subjects, the greatest variability is reached for elbow angle, 21,8 $\pm 8,2^{\circ}$ for right, and $19,8 \pm 8,0^{\circ}$ for left side. Standard deviation is twice greater than for knee, $26,10 \pm 3,7^{\circ}$ for right and $24,88 \pm 4,7^{\circ}$ for left side or ankle, 15,8 $\pm 3,2^{\circ}$ for right, $14,5 \pm 4,5^{\circ}$ for left side. It confirms an expectation that elbow angle will change during gait more between subjects that other two.

One-way ANOVA (Kruskal-Wallis) test was applied to analyze variability. The null hypothesis was that all compared data; gait data of 10 subjects for chosen 1 gait parameter are equal. The alternative hypothesis is that at least one of the means is different. There is between group variation and within group variation expressed mathematically. Then the decision will be to reject the null hypothesis if the test statistic from the calculation is greater than the F critical value. When the decision from the One-Way Analysis of Variance is to reject the null hypothesis, it means that at least one of the means isn't the same as the other means. What we need is a way to figure out where the differences lie, not just that there is a difference. This is where the follow-up tests came into play. We chose Scheffe test to help us analyze pairs of means to see if there is a difference and between which subjects there is significant differences. The Scheffe' test is customarily used with unequal sample sizes, although it could be used with equal sample sizes. The critical value for the Scheffe'test is the degrees of freedom for the between variance times the critical value for the one-way ANOVA $[8,9]$.

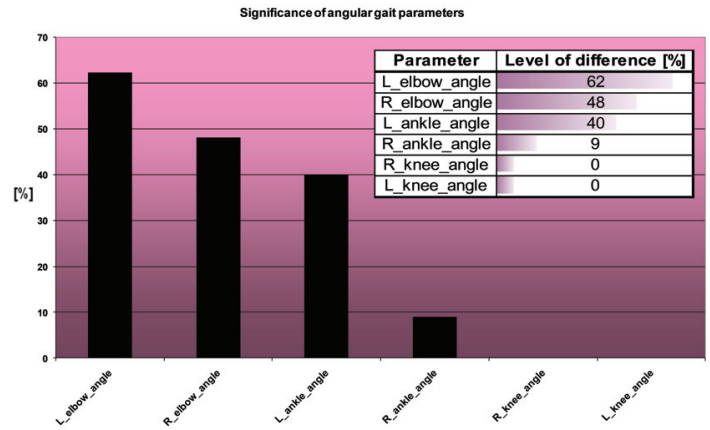

Fig. 13 Order of angular gait parameters according to level of significant differences for 10 measured subjects

The preliminary results of analysis of variance for kinematic angular data indicate that the most variable parameter will be related to higher value of degrees of freedom, range of motion and complexity of joint from physiology point of view. Multiple comparison of angular data results in expressing statistically significant difference using level of difference when comparing the data between

\begin{tabular}{|c|c|c|c|c|c|c|c|c|c|c|c|c|c|c|c|c|c|c|}
\hline Subject & $\min$ & $\max$ & ROM & $\min$ & $\max$ & $\mathrm{ROM}$ & $\min$ & $\max$ & ROM & $\min$ & $\max$ & ROM & $\min$ & $\max$ & $\mathrm{ROM}$ & mIn & $\max$ & रणा \\
\hline$\overline{F 1}$ & 9.76 & 43.82 & 34.06 & 9.09 & 41.93 & 32.84 & 4.69 & 78.24 & 73.55 & 2.21 & 73.66 & 71.45 & 2.09 & 37.03 & 34.95 & 2.78 & 38.83 & 36.05 \\
\hline M1 & 13.65 & 44.93 & 31.29 & 15.05 & 41.42 & 26.37 & 4.35 & 61.96 & 57.62 & 5.08 & 65.21 & 60.13 & 6.68 & 31.98 & 25.31 & 0.09 & 30.98 & 30.89 \\
\hline $\mathrm{F} 2$ & 18.13 & 35.65 & 17.52 & 6.39 & 29.55 & 23.16 & 4.77 & 63.03 & 58.26 & 4.37 & 68.14 & \begin{tabular}{|l|}
63.77 \\
\end{tabular} & 6.87 & 36.68 & 29.82 & 9.70 & 43.33 & 33.63 \\
\hline F3 & 19.02 & 32.30 & 13.28 & 15.06 & 32.79 & 17.72 & 2.15 & 66.66 & 64.51 & 7.07 & 66.89 & 59.81 & 2.47 & 32.49 & 30.03 & -0.25 & 23.81 & 24.06 \\
\hline $\mathrm{M} 2$ & 13.45 & 65.76 & 52.31 & 12.86 & 58.69 & 45.83 & 7.21 & 69.85 & 62.63 & 3.15 & 61.99 & 58.84 & 6.26 & 37.49 & 31.24 & 3.55 & 34.11 & 30.56 \\
\hline M3 & 9.40 & 37.56 & 28.16 & 10.84 & 43.35 & 32.51 & 4.91 & 63.95 & 59.04 & 2.08 & 61.74 & 59.66 & 7.33 & 45.23 & 37.91 & 4.36 & 33.41 & 29.05 \\
\hline M4 & 15.10 & 25.26 & 10.16 & 15.75 & 27.45 & 11.71 & 2.52 & 66.46 & 63.94 & 5.00 & 69.60 & 64.60 & 2.86 & 32.09 & 29.23 & -2.96 & 25.14 & 28.10 \\
\hline F4 & 5.72 & 24.02 & 18.29 & 3.12 & 17.98 & 14.86 & 5.19 & 67.02 & 61.83 & 1.70 & 64.69 & 62.99 & -1.20 & 41.46 & 42.66 & 2.46 & 51.57 & 49.11 \\
\hline M5 & 11.53 & 37.09 & 25.56 & 13.63 & 31.81 & 18.18 & 8.73 & 65.07 & 56.34 & 9.76 & 70.55 & \begin{tabular}{|l|}
60.79 \\
\end{tabular} & 2.00 & 27.49 & 25.49 & -0.66 & 27.58 & 28.23 \\
\hline \multirow[t]{3}{*}{ F5 } & 4.48 & \begin{tabular}{|l|}
19.13 \\
\end{tabular} & \begin{tabular}{|l|}
14.66 \\
\end{tabular} & 3.88 & \begin{tabular}{|l|}
23.04 \\
\end{tabular} & 19.16 & 6.67 & 65.94 & 59.27 & 4.84 & 60.32 & 55.48 & 1.62 & 39.34 & 37.72 & 6.92 & 38.85 & 31.93 \\
\hline & \multicolumn{6}{|c|}{ Right and left elbow angle } & \multicolumn{6}{|c|}{ Right and left knee angle } & \multicolumn{6}{|c|}{ Right and left ankle angle } \\
\hline & \multicolumn{6}{|c|}{ global maximum value of ROM } & & \multicolumn{11}{|c|}{ local maximum value of maximal angle } \\
\hline & \multicolumn{6}{|c|}{ global minimum value of ROM } & & \multicolumn{11}{|c|}{ local minimum value of minimal angle } \\
\hline
\end{tabular}

Fig. 12 Comparison of angular data and range of motion of 3 human joint angles 
subjects. The flexion/extension angle of elbow joint proved over $50 \%$ of significant differences $(p<<0.05)$ and dorsal/plantar flexion of ankle joint shows approximately $40 \%$ of significant differences. Flexion/extension angle of knee joint did not prove sufficient level of statistically significant difference between subjects. Therefore, it is not recommended to become a parameter to distinguish between people in the process of human identification. It must be emphasized that this is result of pilot study where number of subjects involved into study was limited, as well as the amount of data gathered per subject and number of parameters included in the research.

\section{CONCLUSION}

The main focus of our research is in methodology as this complex area of the gait analysis requires systematic and engineering approach. First results of experiments obtained from data analysis show that there are possibilities to create a set of selected gait parameters exploring individual characteristics. Only the gait parameters the most statistically significant differences will enable gait pattern classification. In our research we found out that elbow and ankle angles have the best potential for identification task. Further experimental analysis and data evaluation using SMART analyzer and Matlab will be devoted to identify the algorithms and methods of gait patterns classification.

The qualitative analysis of the physiological gait shows that upper extremities, head and trunk present greater variability and knee and foot movement is less variable. In order to detect significant differences, analysis of variance is suggested to be applied. The quantitative analysis showed that angular kinematic parameters declare the highest variability and also the potential to be used for identification. However, other parameters proving not very high difference can also be important. They though are not very significant among the all included in the set of parameters, it can be anyhow important in the algorithm. e.g. when pathology influences the walking style of person. For further research it is recommended to analyze bigger group of subjects, with more variables and test more possible influences as clothing, loading body during walk $[3,10,11]$.

We decided to use original approach - methodology for application of human motion analysis into identification task. We used the motion tracking system SMART for its advantages of opto-electronic motion systems - precision of optical gait data, easy way to change marker configuration. However, optical system cannot capture motion when markers are occluded for longer period of time, some gait data can be missing and also redundant reflections can occur.

Only after precise data analysis and their statistical difference estimation using mathematical and statistical methods, we can find the set of gait parameters that are the most relevant for human identification. Based on the results of the research in gait pattern analysis, we can set the input for marker free analysis using system MAFRAN developed at our department. This system is using common video camera and can be potentially used for matching the capture from laboratory conditions with record from the crime scene. Based on knowledge of gait pattern achieved using SMART system, marker-free method can focus on the most reliable gait parameters for finding optimal approach in identification task.

\section{ACKNOWLEDGEMENT}

The described research work was done in the Human Motion Analysis Laboratory at Technical University of Košice and was funded by grant VEGA 1/0820/08 "Dynamic Analysis of Human Motion in Clinical Praxis, Rehabilitation and Sports Medicine" and by the project of College of Karlovy Vary Nr. VE20072009007 "Identification of persons according to the functional and dynamic attributes".

\section{REFERENCES}

[1] MAJERNÍK, J., ŠIMŠÍK, D.: Marker-free analysis of human gait. In: EMBEC '05: 3rd European Medical \& Biological Engineering Conference November 20-25, 2005, Prague, Czech Republic: Proceedings. Prague: IFMBE, 4 p., 2005

[2] MAJERNÍK, J.: Rozvoj metód videoanalýzy pohybu človeka pre klinickú prax: Doktorandská dizertačná práca. 190 s., Košice 2004

[3] ŠIMŠÍK, D., PORADA, V., RAK, R., MAJERNÍK, J., GALAJDOVÁ, A.: Analýza pohybu človeka pri identifikácii osôb v kriminalistike. 1. vyd. Košice :TU, SjF, 2008. 272 s. ISBN 978-80-553-0023-8

[4] DOLNÁ, Z., ŠIMŠÍK, D., GALAJDOVÁ, A.: A gait pattern classification based on human motion analysis usign SMART system. In: ESMAC Lon- 
don 2009: 18th Annual Meeting of the European Society of Movement Analysis in Adults and Children: London, 17-19th, 1 p., September 2009

[5] DAVIS, R. B., OUNPUU, S., TYBURSKI, D., GAGE, J. R.: A gait data collection and reduction technique. In: Human Movement Science, pp. 575587, Vo. 10., 1991

[6] KADABA, M. P., RAMAKRISHNAN, H. K., WOOTTEN, M. E.: Measurement of lower extremity kinematics during level walking. In: Journal of Orthopaedic Research, Vol.8. pp. 383-392, No.3. 1990

[7] VAUGHAN, C.L., DAVIS, B.L., O'CONNOR, J.C.: Dynamics of Human Gait. Cape Town: Kiboho Publishers, South Africa, 1999. ISBN 0-62023560-8
[8] One-Way ANOVA. Internet lectures on statistics. Available online:http://people.richland. edu/james/lecture/m170/ch13-1 wy.htmlOne-Way ANOVA, http://people.richland.edu/ james/lecture/m170/ch13-dif.html - post-hoc tests

[9] RIMARČíK, M.: Štatistika pre prax. 1. vyd. 2007.200 s. ISBN 978-80-969813-1-1

[10] NIXON, M.S., TAN, T., CHELLAPPA, R.: Human Identification Based on Gait. New York, USA: Springer, 2006. 187 p. ISBN 978-0-387-24424-2

[11] WINTER, D.: The Biomechanics and Motor Control of Human Gait, 2nd Ed., Ottawa, Canada: Waterloo Biomechanics. 1991

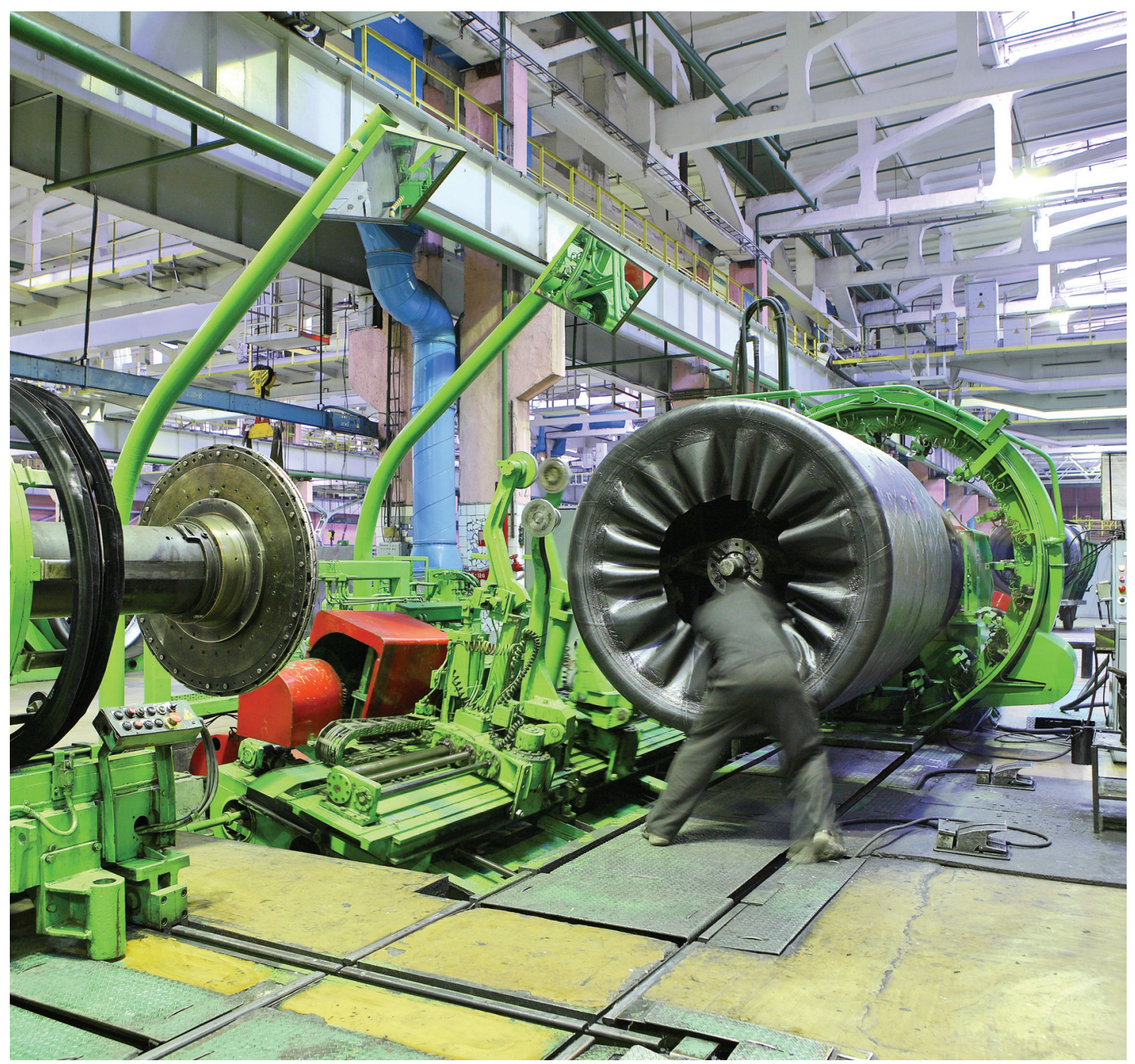

